This document is the accepted manuscript version of the following

article: Rat, M., Mathe-Hubert, H., McKechnie, A. E., Sueur, C., \&

Cunningham, S. J. (2020). Extreme and variable environmental

temperatures are linked to reduction of social network cohesiveness in a

highly social passerine. Oikos, 129(11), 1597-1610.

\title{
Extreme and variable environmental temperatures are linked to reduction of social network cohesiveness in a highly social passerine
}

\author{
Margaux Rat, Hugo Mathe-Hubert, Andrew E. McKechnie, Cedric Sueur and Susan J. Cunningham
}

M. Rat (https://orcid.org/0000-0002-9747-4493) $\square$ (margaux.rat@uct.ac.za) and S. J. Cunningham (https://orcid.org/0000-0001-99342585), FitzPatrick Inst. of African Ornithology, DST-NRF Centre of Excellence, Univ. of Cape Town, Rondebosch, South Africa. - H. Mathe-Hubert (https://orcid.org/0000-0003-4785-433X), Eawag, Swiss Federal Inst. of Aquatic Science and Technology and Inst. of Integrative Biology, ETH, Switzerland. Present address: Centre National de la Recherche Scientifique (CNRS), Lab. Techniques de l'Ingénierie Médical et de la Complexité Informatique, Mathématiques et Applications, Grenoble ((TIMC-IMAG), Grenoble, France. - A. E. McKechnie, FitzPatrick Inst. of African Ornithology, DST-NRF Centre of Excellence, Dept of Zoology and Entomology, Univ. of Pretoria, Hatfield, South Africa, and: South African Research Chair in Conservation Physiology, South African National Biodiversity Inst., Pretoria, South Africa. - C. Sueur (https://orcid.org/0000-0001-8206-2739), Univ. de Strasbourg, CNRS, IPHC UMR, Strasbourg, France, and: Inst. Universitaire de France, Paris, France..

\begin{abstract}
Organisms living in hot, arid environments face important risks associated with hyperthermia and dehydration which are expected to become more severe with cli-mate change. To mitigate these risks, individuals often modify behaviour, e.g. reducing activity and seeking shade. These behavioural modifications may affect interactions between individuals, with consequences for the social structure of groups. We tested whether the social structure of cooperative groups of sociable weavers Philetairus socius varied with environmental temperature. We recorded the nature and frequency of interactions at feeders positioned beneath three sociable weaver colonies $(n=49$ iden-tified birds) in the Kalahari Desert with respect to environmental temperatures over a 30-day period. Using random forest models, we examined whether thermal conditions predicted variation in social network structure. We also conducted focal observations of individual weavers to assess functional links between temperature, intensity of heat dissipation behaviour (panting) and immediate effects on social behaviour. Our results suggest that the social structure of weaver colonies becomes less cohesive and more fragmented at extreme and variable environmental temperatures. These changes in network structure appear to be linked with individuals' heat dissipation behaviour: extreme and variable temperatures were associated with increased panting, which was significantly correlated with an immediate reduction in the frequency of association. Collectively, our results indicate that interactions within groups could be disturbed by environmental temperature variation and extremes. Changing temperature regimes could therefore affect the functioning of animal societies by altering social networks.
\end{abstract}

Keywords: climate change, environmental disturbance, group cohesiveness, social network, temperature variability, thermoregulation costs

Supplementary material (available online as Appendix oik- 07463 at <www.oikosjournal.org/appendix/ oik-07463>). Appendix 1. 


\section{Introduction}

Sociality confers a wide range of direct and indirect fitness benefits (Kramer and Meunier 2016), but social relationships between individuals can be strongly affected by ecological factors. For example, social interactions may be modified when resource availability is reduced, triggering aggression and diminishing affiliative behaviour (Ahola et al. 2007, Kummerli et al. 2010). Furthermore, changing biotic and abiotic conditions under global change are expected to affect competition and other interactions between individuals, and the demography of groups (Both et al. 2006, Sueur et al. 2017, Destoumieux-Garzón et al. 2018). Hence, climate change may indirectly affect the type and frequency of interactions displayed between conspecifics, with implications for group social organisation and the individual fitness benefits of group-living.

Climate change could also affect social interactions directly via the behavioural adjustments animals make when exposed to high temperatures. For example, rising temperatures drive changes in time-activity budgets as individuals retreat to cooler locations within thermal landscapes (Martin et al. 2015, Mason et al. 2017), spend longer periods inactive (Carroll et al. 2015) and/or more time dissipating heat via evaporative cooling pathways (e.g. panting; McKechnie and Wolf 2010). These adjustments for thermoregulation can occur to the detriment of other behaviours, notably foraging (du Plessis et al. 2012, Cunningham et al. 2015, Funghi et al. 2019) and social behaviour (Santee and Bakken 1987); and have been linked to body mass loss and reduced breeding success (du Plessis et al. 2012, Cunningham et al. 2013, Wiley and Ridley 2016, van de Ven et al. 2019).

Sociality and cooperation may be particularly important in harsh and unpredictable environments, e.g. arid savannas (Rubenstein and Lovette 2007). In such environments, many species already live near physiological tolerance limits, experiencing high risks of hyperthermia and dehydration (Wolf 2000). Social bonds between group members may help to maintain individual and group performance under these conditions via reduction of individual costs (Crick 1992, Shen et al. 2017) and promotion of individual benefits such as improved ability to locate food patches and detect predators (Cornwallis et al. 2017). Yet, climate change models predict a faster increase in the frequency and amplitude of heat waves in arid zones than in most regions of the globe (Meehl and Tebaldi 2004, Akoon et al. 2011), and there is already evidence of bird community collapse in response to warming in the Mojave Desert (Iknayan and Beissinger 2018).

Although sociality may reduce costs associated with harsh environmental conditions, very little is known about how sensitive these buffering effects are to increments and/or greater variability in temperature. We test the hypothesis that the social structure of an arid-zone, group-living bird is influenced by high temperatures and/or unpredictable temperature changes via tradeoffs between heat dissipation behaviour and social interactions. We conducted a field-based study to examine whether interactions and relationships between colony members were dependent on environmental temperature. Sociable weavers are passerines endemic to southern Africa. They are long-lived (up to 16 year old; Covas 2012) and colonies roost communally year-round in large cooperatively-built nests so that the same individuals interact frequently and can develop strong social bonds (Maclean 1973c). We explored whether temperature effects were evident in the social network structure of three wild colonies of sociable weavers ( $\mathrm{n}=49$ individuals) in the Kalahari Desert. We predicted that under physiologically stressful high and/or variable temperature conditions, the frequency of affiliative and/or agonistic interactions would be altered, for example due to birds engaging more in heat dissipation and avoidance behaviours (Vasse et al. 2017); and colony social structure would become less dense and more disconnected, reflecting a reduction in group cohesiveness.

\section{Material and methods}

\section{Study site and species}

We worked at Murray Guest Farm, a privately-owned sheep and cattle farm in the Northern Cape Province of South Africa $\left(26^{\circ} 59^{\prime} \mathrm{S}, 20^{\circ} 52^{\prime} \mathrm{E}\right)$, during January and February 2016. Vegetation at the farm is typical of Kalahari arid savanna; characterised by red sand dunes, sparse grass, scattered trees and shrubs dominated by Vachellia erioloba and Senegalia mellifera (Fig. 1). The study was conducted during the austral summer when climate is hot and rainfall occurs as unpredictable, localised thunderstorms (Tyson and Crimp 1998; daily average minimum-maximum air temperature: $18.4-36.8^{\circ} \mathrm{C}$; and rainfall: 0-65.9 mm; data from Twee Rivieren Nov-Feb 1999-2015; provided by the South African Weather Service).

Sociable weavers live year-round in colonial nests which vary greatly in size (van Dijk et al. 2013) and can host from 2 to hundreds of individuals (Maclean 1973a). They build and maintain the nest thatch cooperatively through generations (Maclean 1973b). Each colony forms a distinctive functioning social unit. Individuals of the same colony interact with high frequency over both short and long time-scales, as all colony members roost in the same nest and forage together in gregarious flocks year-round (Flower and Gribble 2012, Ferreira et al. 2020). 'Within the confines of its own colony, the sociable weaver is probably as social as any bird could possibly be' stated Maclean (1973b). As such, interchange of individuals between colonies is low while aggression toward immigrants is high (Maclean 1973b, Rat 2015). Each colony consists of multiple social sub-units of individuals roosting in separate nest chambers with downwards-facing entrances on the underside of the nest (Fig. 1). These units typically constitute of a breeding pair with helpers-at-the-nest, so 2-7 individuals can roost in the same nest chamber (Covas et al. 2008). Helpers are mostly male offspring from previous breeding attempts, but more distantly related individuals also 


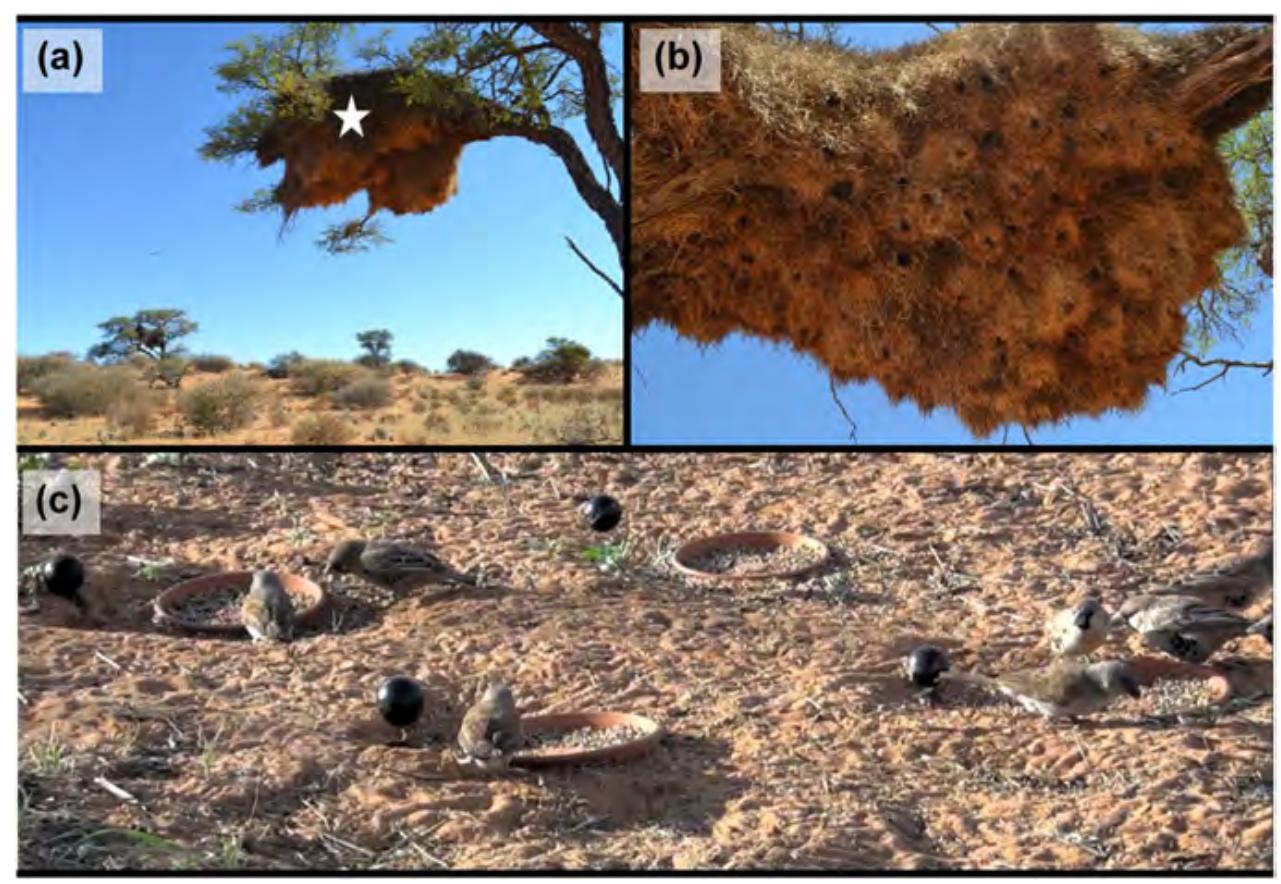

Figure 1. Photographs (a), (b) and (c) of the study system: Photo (a) illustrates the study site in the Kalahari desert. A colonial nest of the study species, the sociable weaver, is indicated by a star. Photo (b) offers a closer view of underneath the colonial nest. The nest is built cooperatively over many generations and it is used year-round for roosting. Photo (c) shows the type of experimental design set up under three colonies of sociable weavers. We recorded the co-occurrence of individuals foraging at the same feeder to establish associations between individuals. The feeders were filled with a seed mixture and a blackbulb thermometer positioned next to each feeder recorded the environmental temperature every $5 \mathrm{~min}$.

help (Doutrelant et al. 2004, Covas et al. 2006, Doutrelant and Covas 2007). During the study period, our study site hosted approximately 70 active sociable weaver colonies, varying in size from 1 to 180 occupied nest chambers (average of 46 occupied chambers per colony).

Between 23 and 28 January 2016, we caught 21, 18 and 11 sociable weavers respectively from three distinct small colonies, hereafter colonies A, B and C (see Covas et al. 2002, van Dijk et al. 2015 for more details on the captures). Each bird was colour-ringed for individual identification. We attempted to catch entire colonies, but five individuals escaped and remained un-ringed (respectively 2, 1 and 2 individuals).

\section{Field experiment}

We positioned artificial feeders ( $8 \mathrm{~cm}$ diameter plastic dishes) with an ad libitum seed mixture at each colony between 26 January and 26 February 2016. Each colony had one feeder per -5 birds to ensure equal possibility of spatial clustering (i.e. $\mathrm{n} / 5$ feeders per colony, where $\mathrm{n}=$ number of birds in the colony). Feeders were located on the ground underneath the nest equidistant from each other (ca $50 \mathrm{~cm}$ apart; Fig. 1). To habituate the weavers to the experimental set-up, a video camera (Sony HDRCX130), tripod and feeders were positioned all day beneath each colony until the first individual was observed to feed (range: 1-5 days). Feeders were then removed and replaced for $2 \mathrm{~h}$ per day per colony, during which time birds were observed visually and with a video-camera. These 2-h observation blocks were rotated between three different time-of-day periods: morning (AM) observations began between 6:30 and 7:15 a.m., corresponding to $30 \mathrm{~min}$ after sunrise; mid-day (MID) observations began between 1:15 and 2:00 p.m., matching the hottest time of the day; and afternoon (PM) observations began between 4:15 and 5:00 p.m. and ended $30 \mathrm{~min}$ prior to sunset. We conducted our observations over short time scales as this appeared to be the most appropriate method to identify meaningful associations between individuals within flocks of this highly gregarious species (Ferreira et al. 2020). Observations were distributed equally between the three colonies and time periods.

\section{Behavioural data; extraction of association networks and social metrics}

Two types of observational data were collected: scan samples extracted from video-camera footage; and focal observations ('focals') of individuals.

Scan samples: For all 2-h observation blocks, the video camera was set up to record activity at all feeders as well as $30-\mathrm{cm}$ around them. We extracted still frames from the footage at 1-min intervals for each 2-h observation block (hereafter 'scan samples'). We regarded the co-occurrence of individuals at the same feeder during the same scan sample as a proxy for social association (Table 1). This measure was used to establish two types of association networks: HWi and instant; for each 2-h observation block.

'HWi networks' were established using identity of colourringed colony members feeding, and the identity of the feeder used ('feeder position'; Table 1). HWi networks are based on 
Table 1. Behavioural data recorded during scan samples from video-recordings and focal observations: their specific nature; the proxy used for collection; and definition. Note that social behaviour collected from focals is directional (initiated or received by the focal individual) while data collected from video-recordings are symmetrical.

\begin{tabular}{|c|c|c|c|c|}
\hline Method & Behav. data & Nature & Proxy & Definition \\
\hline Scan samples & $\begin{array}{l}\text { Network of } \\
\text { associations }\end{array}$ & Co-occurrence & Spatial proximity & Co-occurrence at the same feeder at the same time \\
\hline \multirow[t]{4}{*}{ Focal observations } & $\begin{array}{l}\text { Frequency of } \\
\text { associations }\end{array}$ & Co-occurrence & Spatial proximity & $\begin{array}{l}\text { The focal individual is }<1 / 2 \text { a sociable weaver } \\
\text { body-length away from another individual }\end{array}$ \\
\hline & Heat dissipation & Panting & Time spent panting & Duration of panting by the focal individual \\
\hline & Agonistic interactions & High intensity & $\begin{array}{l}\text { Aggression } \\
\text { Displacement }\end{array}$ & $\begin{array}{l}\text { Focal individual physically attacks another individual. } \\
\text { Focal individual moves in the direction of a second } \\
\text { individual until this individual moves away. }\end{array}$ \\
\hline & & & Threat & $\begin{array}{l}\text { Focal individual makes a movement of the head toward } \\
\text { a second individual until this individual moves away. }\end{array}$ \\
\hline
\end{tabular}

the calculation of the half-weight index (HWi), a measure of affinity between two individuals of a group based on the proportion of time spent together (Whitehead and Dufault 1999). Alternative association indexes could have been used, but as pointed by Hoppitt and Farine (2018), for our type of dataset (only some individuals are missing, not groups), most association indexes are valid for relative associations, scale-free networks and node statistics such as we have here. HWi indices were computed for every possible dyad of colour-ringed weavers that were observed at a feeder at least once per $2 \mathrm{~h}$ observation block. The structure of each HWi network was characterised by a set of social metrics, estimated once per 2-h observation block (Table 2). We excluded unringed sociable weavers to avoid biases due to the impossibility of determining whether the same unringed individuals were sighted during different scan samples within a single observation block (Cairns and Schwager 1987, Whitehead and Dufault 1999). The median number of observations per ringed individual was $194 \pm 71.7$ SD. Three individuals were observed only 1 , 4 and 13 times. These 18 observations represent $0.2 \%$ of all observations and thus have a negligible impact on our results.

'Instant networks' were established to include unringed individuals; as these represented $16 \%$ of birds for all scan samples. For these, we additionally recorded the feeder position of unringed weavers in each scan sample. Instant network structure was characterised by a set of social metrics calculated per scan sample (Table 2) and then averaged to obtain one value per social metric per 2-h observation block.

We included colony identity as a covariate in all analyses to account for effect(s) induced by variation in the number of feeders. Additionally, we estimated network size using the average number of individuals present per scan sample and corrected all social metrics for this variable (Supplementary material Appendix 2; Smith et al. 2017). We also recorded the number of southern grey-headed sparrows Passer griseus (hereafter 'sparrows'; the only other species frequently visiting the feeders and interacting with sociable weavers) per scan sample, to test whether their presence affected the sociable weaver network size and structure.

We use both HWi and instant networks in our analyses because although the instant networks included unidentified and unringed individuals, they also considered each scan sample separately, which oversimplifies the real network (Smith et al. 2017, Hoppitt and Farine 2018, Silk 2018). By contrast, HWi networks capture this complexity by integrating all scan samples from a given 2-h observation block. Using both types of networks allowed us to examine network structure including interactions between known individuals (HWi networks) while also correctly estimating network size by including unringed/unidentified individuals (instant networks).

Focals: During a subset of 27 (from 84) 2-h observation blocks, one observer (MR) conducted focal observations on individual birds from a hide $-10 \mathrm{~m}$ from the colony, to explore links between heat dissipation behaviour (panting) and social behaviours not directly related to a feeding context. During focals, the observer followed a randomly-chosen individual weaver until it approached a feeder or went out of sight. At this point, another individual would be chosen and 'focalled'; avoiding any individuals which had been previously targeted during the observation period. The average focal duration per individual was $263 \pm 172 \mathrm{~s}$ (mean $\pm \mathrm{SE}$ ). During each focal, the observer recorded: 1) the time spent panting (defined as: panting is an heat dissipation behaviour associated with evaporative cooling; Smit et al. 2013); 2) the number of 'affiliations' (defined as the focal individual being less than half a sociable weaver body-length away from another sociable weaver: approximately $7 \mathrm{~cm}$ or less); and 3) the number of four kinds of agonistic interactions the focal individual perpetrated or was subject to (Table 1).

\section{Environmental temperature measurements}

To monitor the temperatures experienced by individuals at the feeders, we used black-bulb thermometers logging at 5-min intervals (Cunningham et al. 2015). These comprised an iButton temperature logger (model DS1922L) within a $30-\mathrm{mm}$ diameter black-painted hollow copper sphere (approximating the dorso-ventral length of a small passerine). Black-bulb thermometers provide a single-number estimate of operative environmental temperature $\left(T_{e n n}\right)$, integrating the effects of wind, air temperature, radiation, conduction and convection. While not able to exactly replicate the heat-load 
Table 2. Social metrics computed to describe network structures. Social networks consist of nodes representing individuals and edges between nodes symbolizing direct association between individuals. Indirect associations (e.g. 'friends-of-friends') are represented by paths formed by a chain of nodes. 'Level' defines whether social metrics were computed at the level of the whole colony network: 'networkbased'; or for each individual within a colony network, then averaged across all individuals in the network: 'individual-based'. With respect to network type, 'HWi' indicates metrics computed for HWi networks established per 2-h observation block. 'Instant' indicates metrics computed for instant networks established per scan sample and then averaged to produce one value per 2-h observation block. Social metrics were corrected for network size.

\begin{tabular}{|c|c|c|c|}
\hline Level & Social metric & Network type & Definition \\
\hline \multirow[t]{6}{*}{ Network-based } & Network size & Instant & The number of individuals at the feeders per scan sample. \\
\hline & Diameter & $\mathrm{HWi}$ & $\begin{array}{l}\text { The shortest number of edges (i.e. distance) between the two most distant } \\
\text { individuals in the network. }\end{array}$ \\
\hline & Isolate & HWi and Instant & Proportion of individuals that did not associate with any other individual. \\
\hline & Cluster size & HWi and Instant & Mean size of groups of interconnected individuals. \\
\hline & Cluster $\mathrm{N}$ & HWi & Number of groups of interconnected individuals. \\
\hline & Average path length & HWi & $\begin{array}{l}\text { A measure of indirect associations based on the average number of } \\
\text { intermediate individuals (i.e. steps) needed to connect two members of the } \\
\text { network. }\end{array}$ \\
\hline \multirow[t]{5}{*}{ Individual-based } & Closeness & HWi & $\begin{array}{l}\text { A measure of indirect association based on the number of intermediate } \\
\text { individuals required for an individual to be connected to every other } \\
\text { individual in its network. }\end{array}$ \\
\hline & Degree & HWi and Instant & $\begin{array}{l}\text { The number of individuals directly connecting/associating with the focal } \\
\text { individual. }\end{array}$ \\
\hline & Strength & HWi & $\begin{array}{l}\text { The number of individuals directly connecting/associating with the focal } \\
\text { individual weighted by the frequency of this association over the 2-h } \\
\text { observation block (weighted Degree). }\end{array}$ \\
\hline & Fidelity & HWi & $\begin{array}{l}\text { The difference between Strength and Degree metrics for each individual. A } \\
\text { high score indicates that an individual tends to associate many times with } \\
\text { only a few other individuals, hence exhibiting high 'fidelity' to those } \\
\text { individuals. }\end{array}$ \\
\hline & $\begin{array}{l}\text { Eigenvalue } \\
\text { centrality }\end{array}$ & HWi & $\begin{array}{l}\text { A measure of approximate importance of each focal individual in their network } \\
\text { based on the number of individuals they directly associate with and the } \\
\text { number of individuals those individuals directly associate with and so on. A } \\
\text { high average value indicates a dense network. }\end{array}$ \\
\hline
\end{tabular}

experienced by a living bird (Bakken et al. 1985), they provide an estimate of thermal conditions and quantify variation in $T_{e n v}$ during the 2-h observation block. We calibrated the iButtons in a water bath against a mercury-in-glass thermometer with NIST-traceable accuracy prior to deployment, following (Cunningham et al. 2015).

For each colony, we positioned a black-bulb thermometer on the ground adjacent to each feeder (Fig. 1) and another in the shade $2 \mathrm{~m}$ above the ground in the colony tree to approximate potential 'thermal refuge' temperatures $\left(T_{e n,}{ }^{\circ} \mathrm{C}\right.$ Tree $)$. Environmental temperature at the feeders $\left(T_{e n v}{ }^{\circ} \mathrm{C}\right.$ Ground $)$ for each colony and time-point was calculated as the average temperature recorded by all feeder-adjacent black-bulbs for that colony.

\section{Statistical analyses}

Statistical analyses were performed using R ver. 3.0 or higher (<www.r-project.org $>$ ).
Temperature variables For each 2-h observation block, we examined the distribution of $T_{e n v}{ }^{\circ} \mathrm{C}$ Ground and $T_{e n v}{ }^{\circ} \mathrm{C}$ Tree. We estimated the lowest, highest and average $T_{e n v}$, using the quantile $0.05\left(Q_{0.05}\right)$, the quantile $0.95\left(Q_{0.95}\right)$ and the mean $\left(\right.$ Mean $\left.T_{e n v}{ }^{\circ} \mathrm{C}\right)$, respectively. We additionally estimated immediate temperature stability by calculating the mean change between measurements at consecutive 5 -min time points $\left(E\left[\left|\Delta T_{\text {env }}{ }^{\circ} C\right|\right]\right)$, temperature range over the 2 -h observation block (Range $\left.T_{e n v}\right)$ and the moments of order $2\left(\operatorname{Var} T_{e n v}{ }^{\circ} \mathrm{C}\right)$, order $3\left(\operatorname{Var}_{3}\right.$ $\left.T_{e n v}{ }^{\circ} \mathrm{C}\right)$ and order $4\left(\operatorname{Var}_{4} T_{e n v}{ }^{\circ} \mathrm{C}\right)$ which respectively measure the variance, the asymmetric variance (i.e. skewness) and the variance due to extreme values of $T_{e n v}$ (Supplementary material Appendix 3; Grubbström and Tang 2006). To evaluate whether past temperatures influenced social behaviour during the 2-h observation block, we used the mean of $T_{e n v}{ }^{\circ} \mathrm{C}$ Ground and $T_{e m}{ }^{\circ} \mathrm{C}$ Tree over either $2 \mathrm{~h}(-2 h$ Mean $\left.T_{e n v}{ }^{\circ} \mathrm{C}\right)$ or $24 \mathrm{~h}\left(-24 h \mathrm{Mean} T_{e n v}{ }^{\circ} \mathrm{C}\right)$ immediately prior to the 2-h observation block. 


\section{Association network and social metrics}

We used a principal component analysis (PCA) to explore the relationships between social metrics for both HWi and instant networks (respectively 14 and 4 social metrics corrected for network size; Table 2) and to summarize the variation in social network structure (Bollen et al. 2009, Viblanc et al. 2016). This PCA approach is commonly used in social network analysis studies with collinear variables (see for instance: Viblanc et al. 2016, Ramos et al. 2019). We retained principal components (PCs) that explained $>15 \%$ of variation using the function testdim of the package ade 4 (Dray et al. 2007, Dray 2008). A sequential Bonferroni correction was applied to the p-values of this test to retain only statistically meaningful variables.

We used random forest models (RFs) with conditional inference trees (Jones and Linder 2015) in the package party (Hothorn et al. 2006) to identify predictors best explaining variation in social network size and structure. We used the $\mathrm{RF}$ approach because it is an appropriate statistical analysis method to account for multicollinearity and high numbers of predictors (Hothorn et al. 2006, Strobl et al. 2008). We fitted one RF for the network size and one RF for each of the three PCs retained, which together summarise $76 \%$ of the variation in the network structure. In these fours $\mathrm{RFs}$, predictor variables included all temperature variables described above, colony identity (Colony), time-period (AM, MID or PM; 'Day Period') and the average number of sparrows ( $N$ Sparrow) present during the 2-h observation block. Following Hapfelmeier and Ulm (2013), we used a permutation approach to estimate p-values for each predictor variable within each RF and adjusted these to keep the false discovery rate (FDR) at 5\% (hereafter FDR; Benjamini and Hochberg 1995, Hapfelmeier and Ulm 2013). We estimated the standardized effect size of each predictor for which FDR-adjusted p-values (hereafter $\mathrm{p}_{\mathrm{ADJ}}$ ) was significant following Cafri and Bailey (2016): and present these $\mathrm{p}_{\mathrm{ADJ}}$-values together with the standardized effect sizes throughout. Standardised effect sizes range from -1 to 1 , where $0=$ no effect. Further details are provided in the Supplementary material Appendix 1.

\section{Heat dissipation behaviour}

For focals $>100$ seconds long (minimum threshold set to ensure accuracy when estimating the frequency of an observed behaviour), we used the same RF model approach to test for relationships between different measures of $T_{e n v}$ and the proportion of time individuals spent panting during focals. We then examined whether panting correlated with immediate social behaviour of individuals, by modelling the number of affiliations and agonistic interactions (combined and by types) using a zero-inflated Poisson GLMM (package $g \operatorname{lmm} A D M B$ ) including the following predictors: proportion of time spent panting (arcsine transformed); period of the day; and focal duration. Individual identity nested in colony identity was included as a random effect. We checked models for overdispersion following (McCullagh and Nelder 1989).

\section{Results}

\section{Environmental temperature}

During the 2-h observation blocks, the variable $T_{e n \nu}{ }^{\circ} \mathrm{C}$ Ground ranged from 17.2 to $54.7^{\circ} \mathrm{C}$ (mean $\pm \mathrm{SD}=38 \pm$ $7.9^{\circ} \mathrm{C}$ ), and the variable $T_{\text {env }}{ }^{\circ} \mathrm{C}$ Tree from 18.5 to $50.2^{\circ} \mathrm{C}$ (mean $\pm \mathrm{SD}=35 \pm 7.2^{\circ} \mathrm{C}$ ). These values were averaged across the three colonies.

\section{Network size}

Instant network size (i.e. average number of sociable weavers feeding within each scan sample for each 2-h observation block) was positively correlated with the range of $T_{e n v}{ }^{\circ} \mathrm{C}$ Ground during the 2-h observation block $\left(\mathrm{p}_{\mathrm{ADJ}}=0.01\right.$, standardised effect size $=0.2$; Fig. 2; Supplementary material Appendix 3) and the average number of sparrows also feeding $\left(\mathrm{p}_{\mathrm{ADJ}}=0.01\right.$, standardised effect size $=0.1$; Fig. 2; Supplementary material Appendix 1 Table A4). Network size was also affected by colony identity $\left(\mathrm{p}_{\mathrm{ADJ}}=0.01\right.$, standardised effect sizes from -0.1 to 0.1 depending on colony; Fig. 2; Supplementary material Appendix 3); independently of colony size.

\section{Association networks}

We constructed 84 HWi networks: 30 for AM, 28 for MID and 26 for PM time periods; and 120 instant networks per HWi network. A total of 49 ringed individuals were involved in all HWi networks combined. Feeder visits and social associations were recorded on average 182.1 times per ringed individual (8921 feeder visits recorded in total). In addition, 1742 feeder visits by unringed or unidentified individuals were recorded.

Three principal components (PCs) explained $76 \%$ of the variance in the set of social metrics; controlling for network size. $\mathrm{PC}_{1}$ explained $42 \%$ of the variance and characterized network 'cohesiveness'. High loadings on $\mathrm{PC}_{1}$ indicate: a dense HWi network; low proportion of isolated individuals in both HWi and instant networks; and few, large, clusters of individuals with high degree and strength but low fidelity (Fig. 3). $\mathrm{PC}_{2}$ explained $18 \%$ of the variance and characterized network cohesiveness of dense instant networks rather than $\mathrm{HWi}$ networks (Supplementary material Appendix 4-A). $\mathrm{PC}_{3}$ explained $16 \%$ of the variance and characterized 'cluster fragility': high loadings indicate HWi networks with high path length; high betweenness; high diameter; and low eigenvalue: i.e. fragile cluster(s) reliant mostly on indirect and weak connections between individuals (Supplementary material Appendix 5-A).

\section{Social network cohesiveness ( $P C_{1}$ )}

High variation in $T_{e n v}{ }^{\circ} \mathrm{C}$ Ground correlated with reduced HWi network cohesiveness $\left(\mathrm{PC}_{1}\right)$. This effect was statistically significant for three measures of temperature variability: range; variance (moment 2); and variance due to incidences of 


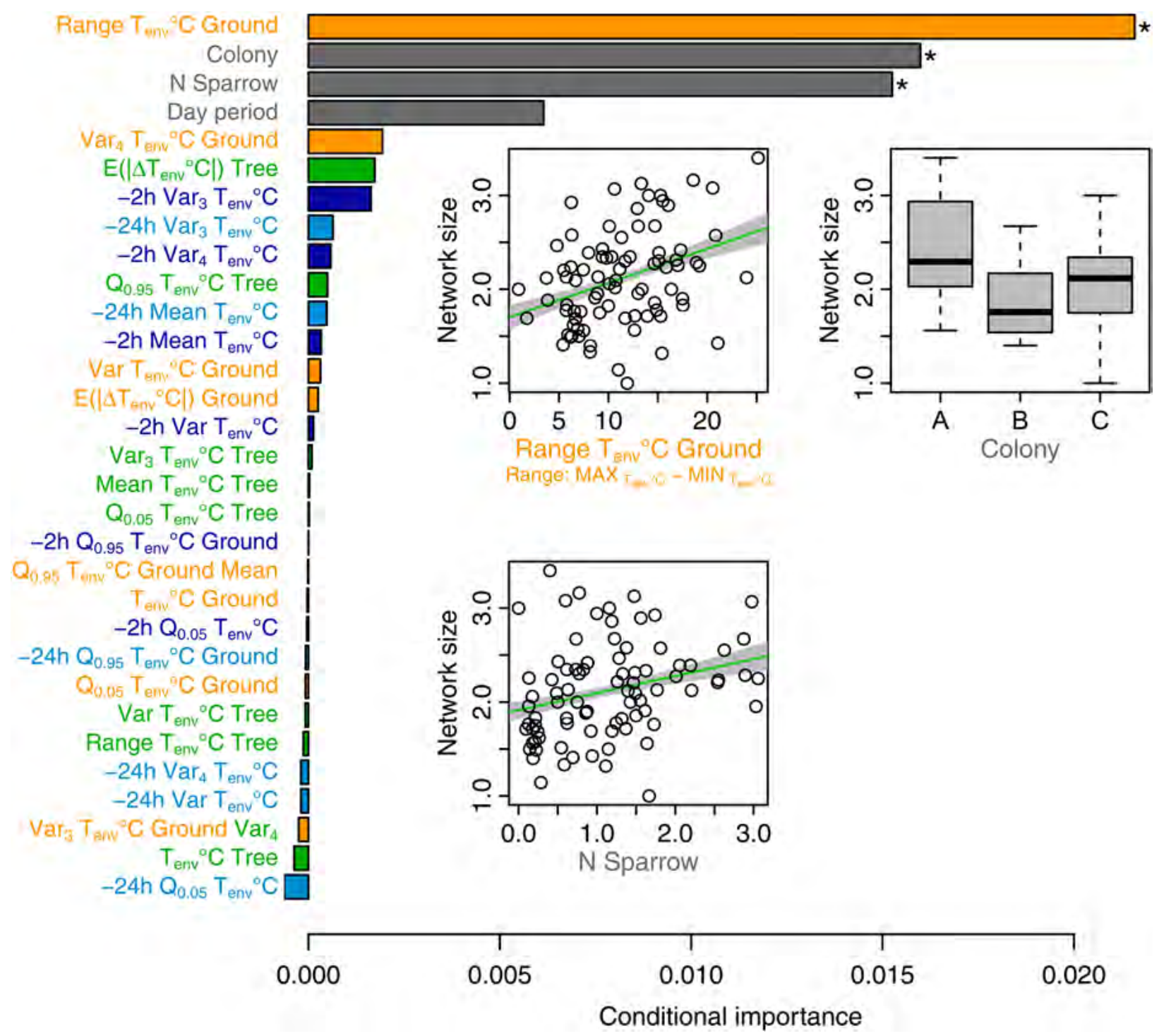

Figure 2. Factors associated with variation in average instant network size. Coloured horizontal bars (left) indicate predictor conditional importance, including both simple and interactive effects, estimated from a random forest model. Orange bars: temperatures recorded on the ground next to feeders $\left(T_{e n v}{ }^{\circ} \mathrm{C}\right.$ Ground); green bars: temperatures in the tree hosting the colonial nest $\left(T_{\text {env }}{ }^{\circ} \mathrm{C}\right.$ Tree $)$; blue bars: mean of ground and tree temperatures recorded over the preceding $2 \mathrm{~h}\left(-2 \mathrm{~h} T_{e n v}{ }^{\circ} \mathrm{C}\right.$, dark blue $)$ or $24 \mathrm{~h}\left(-24 \mathrm{~h} T_{e n v}{ }^{\circ} \mathrm{C}\right.$, light blue). Stars at the end of a bar indicate FDR-adjusted statistical significance (e.g. $\left.{ }^{*}=\mathrm{p}_{\mathrm{ADJ}}<0.05\right)$. Inset plots show relationships between significant predictors and network size, with fitted linear regressions (green line) \pm SE (grey shading). Predictor abbreviations: $N$ sparrow $=$ average number of sparrows present in each scan sample; Day Period=AM, MID or PM observation period; Range $T_{\text {env }}{ }^{\circ} \mathrm{C}=$ the difference between the maximum and minimum environmental temperature recorded during the 2-h observation period; Var, Var 3 and $\operatorname{Var}_{4}=$ respectively the variance of moment of order 2, 3 and 4. $Q_{0.05} T_{e n v}{ }^{\circ} \mathrm{C}$ and $Q_{0.95} T_{e n v}{ }^{\circ} \mathrm{C}=5$ and $95 \%$ quantiles of environmental temperature; $E\left(\left|\Delta T_{\text {env }}{ }^{\circ} C\right|\right)=$ average absolute value of the difference between two consecutive $T_{e n v}{ }^{\circ} \mathrm{C}$ measurements (i.e. a measure of the magnitude of fine scale temperature oscillations).

extreme $T_{\text {env }}{ }^{\circ} \mathrm{C}$ Ground relative to the mean (moment 4) $\left(\mathrm{p}_{\mathrm{ADI}}{ }^{-}\right.$ values $=0.03,0.02$ and 0.02 ; standardised effect sizes $=-0.4$, -0.7 and -0.6 , respectively; Fig. 4 and Supplementary material Appendix 3). This reduction in $\mathrm{HWi}$ network cohesiveness was 2-3.5 times larger than the concomitant increase in network size with increased $T_{e n v}{ }^{\circ} \mathrm{C}$ Ground range (Supplementary material Appendix 3). Network cohesiveness also differed more between colonies than did network size (standardised effect sizes $=-0.2,0.6$ and $-0.3 ; \mathrm{p}_{\mathrm{ADJ}}=0.02$; Fig. 2 and Supplementary material Appendix 3). No other variable tested significantly predicted variation in $\mathrm{PC}_{1} \cdot \mathrm{PC}_{2}$ and the $\mathrm{PC}_{3}$ were mostly explained by respectively a positive effect of the number of sparrows and the identity of the colony (Supplementary material Appendix 3).

\section{Heat dissipation behaviour}

Seven variables related to $T_{e n v}$ were important in explaining the time spent panting by individuals during focals (Fig. 5, Supplementary material Appendix 3). Hot 


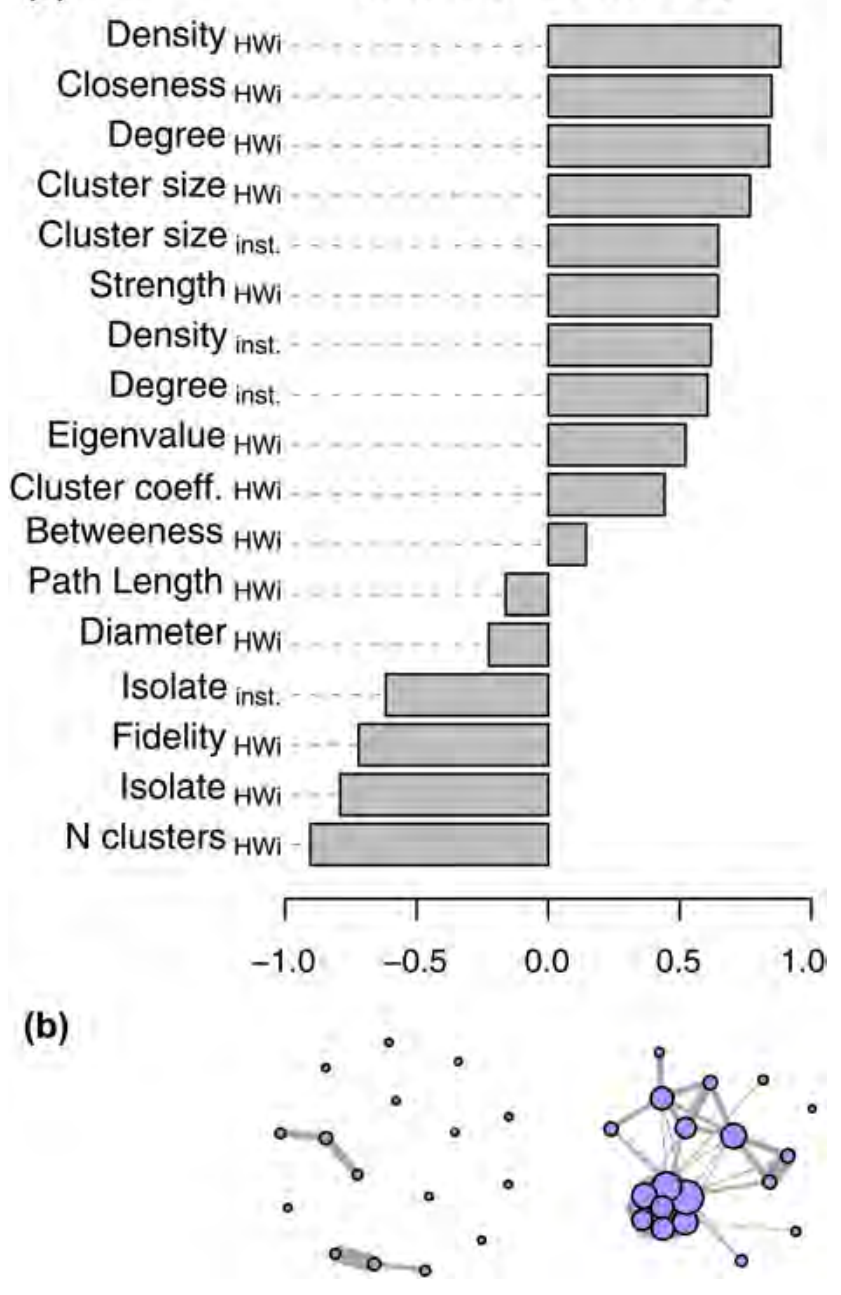

associate with conspecifics, estimate $\pm \mathrm{SE}=-0.27 \pm 0.08 ; \mathrm{p}$ $<0.001$; controlling for focal duration and the period of the day. There was more chance of observing the focal individual associating with a conspecific when the focal was longer: estimate $\pm S E=0.09 \pm 0.31 ; p=0.003$; and when observations were conducted later in the day: estimate $\pm \mathrm{SE}=0.35$ $\pm 0.11 ; \mathrm{p}=0.001$ (Table 3).

However, there was no effect of the proportion of time spent panting on the number of active (estimate $\pm S E=-0.10$ $\pm 0.11 ; \mathrm{p}=0.39$ ) or passive (estimate $\pm \mathrm{SE}=-0.18 \pm 0.11$; $\mathrm{p}=0.09)$ agonistic interactions displayed by individuals. The number of passive agonistic interactions varied only with day period; with 0.28 agonistic interactions displayed on average per individual during mid-day (MID) versus 0.51 in the evening $(\mathrm{PM})$. All other covariates were not significant $(\mathrm{p}>0.08)$.

\section{Discussion}

Environmental changes have the potential to affect relationships between individuals, in turn altering the social structure of cooperative groups and potentially affecting their functioning (Rubenstein 1992, Leu et al. 2016). We tested whether natural variation in environmental temperature was correlated with the social network topology of free-living colonies of sociable weavers observed in a foraging context. Over short time-scales, network cohesiveness was reduced when temperatures were extreme and variable; despite an increase in the size of the network when sociable weavers were experiencing a large range of temperatures. In addition, high and variable temperatures were associated with individual birds spending a greater proportion of time panting: an indication they were

Figure 3. Social networks characterised by $\mathrm{PC}_{1}$ : 'network cohesiveness'. (a) Correlation of social metrics defined in Table 2 to $\mathrm{PC}_{1}$. (b) Visualisation of social network structures with low (left) versus high (right) loadings on $\mathrm{PC}_{1}$. Nodes (individuals) are represented by circles, edges (social associations) by straight lines. Circle size indicates the number of associations involving the individual. Edge thickness indicates the number of associations between the two connected individuals. Metrics were controlled for network size; $\mathrm{n}=84$ sociable weaver networks.

$\left(Q_{0.95} T_{e n v}{ }^{\circ} \mathrm{C}\right.$ Ground $)$ and variable and extreme temperatures (Var ${ }_{4} T_{e n v}{ }^{\circ} \mathrm{C}$ Ground) had the strongest effects, mostly because of their interaction (standardised effect sizes $=0.06,0.04$ and 0.2 for effects in interaction; $\mathrm{p}_{\mathrm{ADJ}}=0.008$ and 0.008 ; Fig. 5 , Supplementary material Appendix 3). Panting was initiated when the hottest temperatures experienced (i.e. $Q_{0.95} T_{e n v}$ Ground) were $\geq 41.5^{\circ} \mathrm{C}$ (value determined by analysing the partial dependency plot; not shown). Once initiated, panting duration (as a proportion of the duration of the focal) increased when temperatures were variable, correlated with the presence of frequent instances of extreme temperature (high $\operatorname{Var}_{4}$ ) (Fig. 5).

The proportion of time individuals spent panting was significantly negatively correlated with their propensity to expending water (employing evaporative heat loss) to maintain body temperatures below lethal limits. Individual sociable weavers showed significantly reduced levels of association with conspecifics while panting; but stable levels of agonistic behaviour. This suggests the reduction in social cohesiveness we observed may have been mediated via reduction in overall affiliative behaviour.

\section{The importance of social cohesiveness}

Social cohesiveness is an extremely important mediator of the fitness benefits of sociality. For example, theoretical models show that social cohesiveness regulates the extent of cooperative behaviour displayed in social groups and the amount of information exchanged between individuals (PugaGonzalez et al. 2018, Romano et al. 2018). Empirical studies show that social cohesiveness also favours protection against predators (Krause and Ruxton 2002, Handegard et al. 2012) and increased foraging success (Tanner and Jackson 2012). In primates, well-connected individuals with strong social bonds to others within their social groups may have higher survival (Alberts 2019), and higher reproductive success than more poorly connected individuals (Silk et al. 2003, Silk $2007 \mathrm{a}, \mathrm{b})$. The advantages conferred by sociality may buffer 


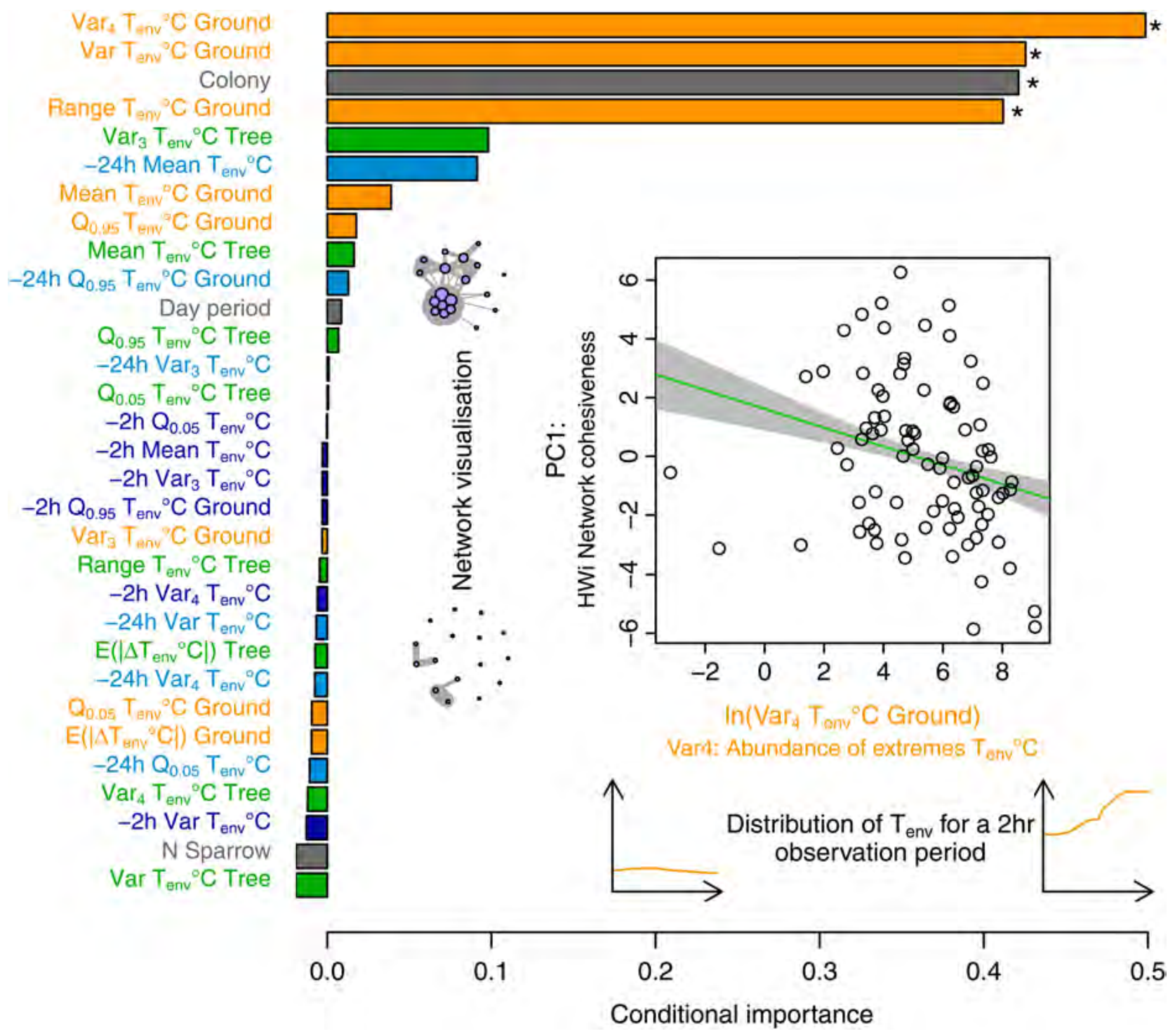

Figure 4. Factors associated with the variation in $\mathrm{PC}_{1}$ : HWi network cohesiveness. Coloured horizontal bars (left) indicate conditional importance of predictors, including both simple and interactive effects, as estimated by a random forest model. Stars at the end of a bar indicate FDR-adjusted statistical significance (e.g. $\left.{ }^{*}=\mathrm{p}_{\mathrm{ADJ}}<0.05\right)$. Inset scatterplot: the effect of $\operatorname{Var}_{4} T_{\text {env }}{ }^{\circ} \mathrm{C}$ Ground on PC ${ }_{1}(\mathrm{HWi}$ network cohesiveness), with fitted linear regression (green line) \pm SE (grey shading). Left of the scatterplot: visualisations of social networks with high (upper network) and low (lower network) values of $\mathrm{PC}_{1}$. Below the scatterplot: example distributions of $T_{\text {env }}{ }^{\circ} \mathrm{C} G r o u n d$ over a 2 -h observation block with low (left) and high (right) Var. Bar colours and predictor abbreviations as for Fig. 2.

individuals against environmental harshness and unpredictability, perhaps explaining the overrepresentation of social species in arid environments (Cornwallis et al. 2017).

Sociable weavers are one such arid-zone social species. Their distribution is centred on southern Africa's Kalahari Desert (Spottiswoode 2005), an area warming rapidly under climate change (van Wilgen et al. 2015). Sublethal fitness losses linked to behavioural responses to high temperatures have already been documented in several arid-zone species (du Plessis et al. 2012, Cunningham et al. 2013, 2015, Catry et al. 2015, van de Ven et al. 2019. It is increasingly clear that cumulative, sublethal fitness costs may threaten population persistence under ongoing climate change, even if temperatures exceeding physiological tolerance limits are not reached (Conradie et al. 2019). Fitness losses associated with the reduction of social cohesiveness are therefore of serious conservation concern for species like sociable weavers; especially if these effects become widespread as a consequence of climate change.

\section{The role of panting behaviour}

In this study, social cohesiveness co-varied with variable temperatures, while panting behaviour co-varied with both hot and variable temperatures. Environmental temperatures on the ground during this study were generally high $\left(\right.$ mean $38^{\circ} \mathrm{C}$ ) and close to sociable weaver normothermic body temperature $\left(41^{\circ} \mathrm{C}\right.$; Whitfield et al. 2015). In addition, 2-h observation blocks during which temperatures were extremely hot (frequently well above weaver body temperature) were associated 


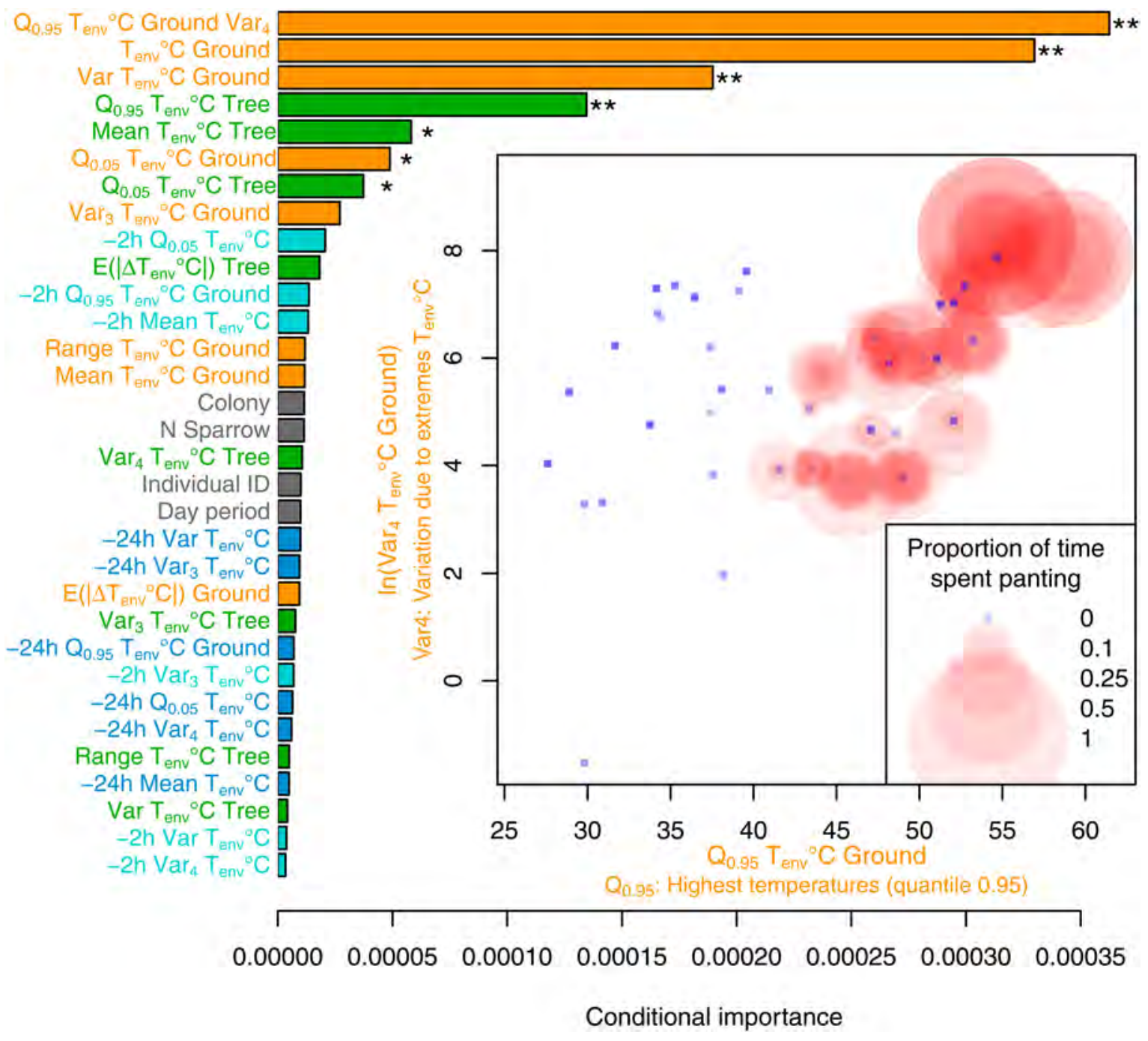

Figure 5. Factors associated with variation in heat dissipation behaviour displayed by focal individuals (i.e. proportion of time spent pant-ing). Coloured horizontal bars (left) indicate conditional importance of predictors, including both simple and interactive effects, as esti-mated by a random forest model. Stars at the end of a bar indicate level of statistical significance $\left(\right.$ e.g. $\left.{ }^{*}=\mathrm{p}_{\mathrm{ADJ}}<0.05\right)$. The scatterplot inset shows the interactive effect of $Q_{0.95} T_{e n v}{ }^{\circ} \mathrm{C}$ Ground and $\operatorname{Var}_{4} T_{e n v}{ }^{\circ} \mathrm{C}$ Ground, the two variables with the highest conditional importance on the proportion of time spent panting. Each symbol corresponds to one individual weavers in a focal observation). Bar colours and predictor abbreviations as for Fig. 2.

high variance in temperature because of extreme values $\left(\operatorname{Var}_{4}\right.$ $T_{e n v} C^{\circ}$ Ground; Fig. 4). Under these conditions, maintaining body temperature below lethal limits is possible only via evaporative cooling, the major avenue of which in sociable

Table 3. Parameter estimates from a zero-inflated Poisson GLMM investigating the number of associations exhibited by an individual in relation to the proportion of focal time spent panting $(n=498$ focals for 54 individuals). Zero-inflation was estimated at 0.123 .

\begin{tabular}{lrrr}
\hline Variable & Estimate \pm SE & Z value & \multicolumn{1}{c}{$\mathrm{p}$} \\
\hline Intercept & $-0.39 \pm 0.14$ & -2.77 & 0.006 \\
Proportion of panting & $-0.27 \pm 0.08$ & -3.49 & $<0.001$ \\
Duration of focal & $0.09 \pm 0.31$ & 2.93 & 0.003 \\
Day period (AM, MID, PM) & $0.35 \pm 0.11$ & 3.21 & 0.001 \\
\hline
\end{tabular}

weavers is panting. Because panting is associated with an immediate reduction in affiliative behaviour, it may be involved in the mediation between temperature and reduction in network cohesiveness. Panting has been shown to tradeoff against other important behaviours, notably foraging, with implications for fitness in other arid-zone birds (du Plessis et al. 2012, van de Ven et al. 2019). Under extremely hot conditions where the immediate risk of lethal hyperthermia is high, heat dissipation via panting is critical and might be favoured over the maintenance of social relationships.

Panting is widespread among birds and is the primary avenue of evaporative cooling in passerines and several other taxa (Dawson 1982). In these groups, panting is routine during hot conditions and often occurs while body temperatures are still well within the normothermic range (McKechnie et al. 
2017, Thompson et al. 2018). However, in some taxa evaporative heat loss is less dependent on panting; among columbids most evaporative heat loss occurs via cutaneous evaporation, and taxa including caprimulgids, quails, cuckoos and sandgrouse make use of gular flutter, a rapid pulsation of the hyoid bone that ventilates the buccal cavity (Lasiewski and Seymour 1972, Marder et al. 1986, Smit et al. 2018). Assuming the temperature-dependence of social cohesiveness we documented here in sociable weavers is indeed functionally linked to panting behaviour, we predict that social cohesiveness is likely to be affected at high temperatures in other taxa which rely on this mechanism for thermoregulation (e.g. other passerine birds); but perhaps less so in taxa in which panting is not the primary mechanism of thermoregulation in the heat (e.g. columbids).

\section{Interindividual variation and the emergence of 'isolates'}

Avian responses to heat may vary among species, between (Noakes et al. 2016) and within populations (Cunningham et al. 2017). In sociable weavers, dominant birds seem better able to maintain stable body temperatures than subordinates when exposed to high air temperatures (Cunningham et al. 2017). In the present study, reduction of social network cohesiveness included the emergence of isolated individuals without any social connections. If the management of thermal challenges results in reduction of social behaviour (this study), and subordinate sociable weavers struggle most with thermal loads (Cunningham et al. 2017), it seems possible these isolates are subordinate birds. We therefore speculate that already-vulnerable individuals may become more vulnerable to the loss of benefits of sociality under thermally challenging conditions. However, subordinates play important roles in the functioning of societies (Crick 1992) and their increased vulnerability may compound the vulnerability of the group.

\section{Conclusions}

To the best of our knowledge, our data provide the first evidence that short-term temperature variation could impact social network structure of a co-operative species, reducing the cohesiveness of social groups and thus potentially increasing the vulnerability of societal systems. Furthermore, social cohesiveness responded to the frequency of temperatures that were extreme with respect to the current mean temperature. This adds evidence of the importance of increases in temperature variation in terms of impacts on species (Ruel and Ayres 1999, Vasseur et al. 2014).

The conclusions drawn here are based on a study of three colonies of sociable weavers in the Kalahari Desert and therefore need to be treated with caution. Nonetheless, social network cohesiveness was reduced consistently across all three groups of birds under highly variable temperatures including hot temperature extremes; and $\mathrm{n}=49$ colour-ringed and identifiable individuals showed reduction in affiliative behaviour under thermally stressful conditions; suggesting that social behaviour may indeed be vulnerable to changing environmental conditions over short time-scales. These reductions in the number of social interactions over short timescales may have longer term consequences for social benefits such as the transfer of information and cooperation; but this remains unknown.

Given the overrepresentation of social species in hot and arid zones (Cornwallis et al. 2017) and the vulnerability of these regions to climate warming (Easterling et al. 2000, Allen et al. 2014), our results warrant further investigation. Further research is needed to identify whether other social species show similar reductions in social network cohesiveness under short-term thermal stress and identify the longer-term impacts for individual fitness and group survival. Despite the unknowns, our results overall raise concern about the potential vulnerability of social species in arid zones under ongoing and severe increases in the frequency of extreme climatic events.

\section{Speculations}

Our study showed that environmental temperature interacts with more traditionally studied socio-ecological factors (e.g. food distribution and predation) to modify network topology in cooperative groups. This suggests that global heating will perturb social networks and modify their topology. Given the alarming rate and global pervasiveness of climate change, loss of network cohesiveness could impact virtually any social species, including our own. Individuals' social behavior is adapted to maximize the benefits of group-living while limiting the costs. Their set of social behaviors is reflected in social network topology, highlighting its determinant role in predicting the success of cooperative groups. A change in network topology within a cooperative group may cause reduced access to resources (food, mates or information) and lower cooperative benefits. Collective behaviors such as migration and/cultural transmission (innovation, language) may be further hindered. Thus, a decrease in network cohesiveness is likely to impair the functioning of social groups and reduce individual fitness. Humans may be particularly susceptible to the psychological impacts of network fragmentation and isolation of individuals. Consequently, global changes have cascading effects on social groups and their members, which are likely to create serious societal risks for future societies.

\section{Data availability statement}

Data are available from the Figshare Digital Repository: <https://figshare.com/s/6682542fdca315a109d1> (doi: $10.6084 / \mathrm{m} 9$.figshare.12865547) (Rat et al. 2020).

Acknowledgements - L. Lefevbre, A. Mbangwa and R. Soller for help with the video analyses; and M. Thompson, M. Noakes, B. Smit, M. Ryo and M. K. Thomas for helpful discussions. 
Funding - This research was supported by the Univ. of Pretoria, the DST-NRF Centre of Excellence at the FitzPatrick Inst. of African Ornithology, Univ. of Cape Town and the CNRS at the Inst. Pluridisciplinaire Hubert Curien, and the National Research Foundation (grant 119754 to AEM). The opinions, findings and conclusions are those of the authors alone, and the National Research Foundation accepts no liability whatsoever in this regard. Author contributions - MR and SJC conceived and designed the study with input from CS and AEM. MR collected data in the field. MR and HM-H analysed the data. MR, SJC, HM-H, AEM and CS contributed to the manuscript write-up. SJC, AEM and CS funded the research.

Conflicts of interest - The authors declare no conflicts of interest.

Permits - The Rossouw family of Murray Guest Farm kindly authorized research on their property. The project was conducted with ethical approval from the Universities of Pretoria and Cape Town (EC041-15 and 2016/v10/SC) and with permission from the Northern Cape Dept of Environment and Nature Conservation (FAUNA 1339/2016). Bird ringing was performed under SAFRING permit no. 12886 and the collection of blood samples under South African Veterinary Council certification no. AL16/15771.

\section{References}

Ahola, M. P. et al. 2007. Climate change can alter competitive relationships between resident and migratory birds. - J. Anim. Ecol. 76: 1045-1052.

Akoon, I. et al. 2011. South African risk and vulnerability atlas. - Dept of Science and Technology, Pretoria.

Alberts, S. C. 2019. Social influences on survival and reproduction: insights from a long-term study of wild baboons. - J. Anim. Ecol. 88: 47-66.

Allen, M. R. et al. 2014. IPCC fifth assessment synthesis reportclimate change 2014 synthesis report. - <www.ipcc.ch/report/ ar $5 /$ syr $/>$

Bakken, G. S. et al. 1985. Operative and standard operative temperature: tools for thermal energetics studies. - Am. Zool. 25: 933-943.

Benjamini, Y. and Hochberg, Y. 1995. Controlling the false discovery rate: a practical and powerful approach to multiple testing. - J. R. Stat. Soc. B 57: 289-300.

Bollen, J. et al. 2009. A principal component analysis of 39 scientific impact measures. - PLoS One 4: e6022.

Both, C. et al. 2006. Climate change and population declines in a long-distance migratory bird. - Nature 441: 81-83.

Cafri, G. and Bailey, B. A. 2016. Understanding variable effects from black box prediction: quantifying effects in tree ensembles using partial dependence. - J. Data Sci. 14: 67-95.

Cairns, S. J. and Schwager, S. J. 1987. A comparison of association indices. - Anim. Behav. 35: 1454-1469.

Carroll, J. M. et al. 2015. Thermal patterns constrain diurnal behavior of a ground-dwelling bird. - Ecosphere 6: 222.

Catry, I. et al. 2015. Differential heat tolerance in nestlings suggests sympatric species may face different climate change risks. - Clim. Res. 66: 13-24.

Conradie, S. R. et al. 2019. Chronic, sublethal effects of high temperatures will cause severe declines in southern African aridzone birds during the 21 st century. - Proc. Natl Acad. Sci. USA 116: 14065-14070.

Cornwallis, C. K. et al. 2017. Cooperation facilitates the colonization of harsh environments. - Nat. Ecol. Evol. 1: 0057.
Covas, R. 2012. The benefits of long-term studies: 16-year old sociable weaver caught at Benfontein Game Reserve. - Safring News 41: 11-12.

Covas, R. et al. 2002. Stabilizing selection on body mass in the sociable weaver (Philetairus socius). - Proc. R. Soc. B 269: 1905-1909.

Covas, R. et al. 2006. Kin associations and direct vs indirect fitness benefits in colonial cooperatively breeding sociable weavers Philetairus socius. - Behav. Ecol. Sociobiol. 60: 323-331.

Covas, R. et al. 2008. Helpers in colonial cooperatively breeding sociable weavers (Philetairus socius) contribute to buffer the effects of adverse breeding conditions. - Behav. Ecol. Sociobiol. 63: 103-112.

Crick, H. 1992. Load-lightening in cooperatively breeding birds and the cost of reproduction. - Ibis 134: 56-61.

Cunningham, S. J. et al. 2013. Temperatures in excess of critical thresholds threaten nestling growth and survival in a rapidly-warming arid savanna: a study of common fiscals. - PLoS One 8: e74613.

Cunningham, S. J. et al. 2015. Can behaviour buffer the impacts of climate change on an arid-zone bird? - Ostrich 86: 119-126.

Cunningham, S. J. et al. 2017. It's cool to be dominant: social status alters short-term risks of heat stress. - J. Exp. Biol. 220: $1558-1562$.

Dawson, W. R. 1982. Evaporative losses of water by birds. - Comp. Biochem. Physiol. A Physiol. 71: 495-509.

Destoumieux-Garzón, D. et al. 2018. The one health concept: 10 years old and a long road ahead. - Front. Vet. Sci. 5: 14.

Doutrelant, C. and Covas, R. 2007. Helping has signalling characteristics in a cooperatively breeding bird. - Anim. Behav. 74: 739-747.

Doutrelant, C. et al. 2004. Unexpected sex ratio adjustment in a colonial cooperative bird: pairs with helpers produce more of the helping sex whereas pairs without helpers do not. - Behav. Ecol. Sociobiol. 56: 149-154.

Dray, S. 2008. On the number of principal components: a test of dimensionality based on measurements of similarity between matrices. - Comput. Stat. Data Anal. 52: 2228-2237.

Dray, S. et al. 2007. The ade4 package: implementing the duality diagram for ecologists. - J. Stat. Softw. 22: 1-20.

du Plessis, K. L. et al. 2012. The costs of keeping cool in a warming world: implications of high temperatures for foraging, thermoregulation and body condition of an arid-zone bird. - Global Change Biol. 18: 3063-3070.

Easterling, D. R. et al. 2000. Climate extremes: observations, modeling and impacts. - Science 289: 2068-2074.

Ferreira, A. C. et al. 2020. How to make methodological decisions when inferring social networks. - Ecol. Evol. 7: ece3.6568.

Flower, T. P. and Gribble, M. 2012. Kleptoparasitism by attacks versus false alarm calls in fork-tailed drongos. - Anim. Behav. 83: 403-410.

Funghi, C. et al. 2019. High air temperatures induce temporal, spatial and social changes in the foraging behaviour of wild zebra finches. - Anim. Behav. 149: 33-43.

Grubbström, R. W. and Tang, O. 2006. The moments and central moments of a compound distribution. - Eur. J. Operat. Res. 170: 106-119.

Handegard, N. O. et al. 2012. The dynamics of coordinated group hunting and collective information transfer among schooling prey. - Curr. Biol. 22: 1213-1217.

Hapfelmeier, A. and Ulm, K. 2013. A new variable selection approach using random forests. - Comput. Stat. Data Anal. 60: 50-69. 
Hoppitt, W. J. and Farine, D. R. 2018. Association indices for quantifying social relationships: how to deal with missing observations of individuals or groups. - Anim. Behav. 136: 227-238.

Hothorn, T. et al. 2006. Unbiased recursive partitioning: a conditional inference framework. - J. Comput. Graph. Stat. 15: 651-674.

Iknayan, K. J. and Beissinger, S. R. 2018. Collapse of a desert bird community over the past century driven by climate change. - Proc. Natl Acad. Sci. USA 115: 8597-8602.

Jones, Z. and Linder, F. 2015. Exploratory data analysis using random forests. - In: Paper presented at the 73rd annual MPSA conference.

Kramer, J. and Meunier, J. 2016. Kin and multilevel selection in social evolution: a never-ending controversy? - F1000Research 5: 776.

Krause, J. and Ruxton, G. D. 2002. Living in groups. - Oxford Univ. Press.

Kummerli, R. et al. 2010. Repression of competition favours cooperation: experimental evidence from bacteria. - J. Evol. Biol. 23: 699-706.

Lasiewski, R. C. and Seymour, R. S. 1972. Thermoregulatory responses to heat stress in four species of birds weighing approximately 40 grams. - Physiol. Zool. 45: 106-118.

Leu, S. T. et al. 2016. Environment modulates population social structure: experimental evidence from replicated social networks of wild lizards. - Anim. Behav. 111: 23-31.

Maclean, G. L. 1973a. The sociable weaver, part 1: description, distribution, dispersion and populations. - Ostrich 44: 176-190.

Maclean, G. L. 1973b. The sociable weaver, part 2: nest architecture and social organization. - Ostrich 44: 191-218.

Maclean, G. L. 1973c. The sociable weaver, part 5: food, feeding and general behaviour. - Ostrich 44: 254-261.

Marder, J. et al. 1986. Cutaneous evaporation in heat-stressed spotted sandgrouse. - Condor 88: 99-100.

Martin, R. O. et al. 2015. Elevated temperatures drive fine-scale patterns of habitat use in a savanna bird community. - Ostrich 86: $127-135$.

Mason, T. H. et al. 2017. The behavioral tradeoff between thermoregulation and foraging in a heat-sensitive species. - Behav. Ecol. 28: 908-918.

McCullagh, P. and Nelder, J. A. (eds) 1989. Generalized linear models, 2nd edn., Vol. 37. - Chapman and Hall.

McKechnie, A. E. and Wolf, B. O. 2010. Climate change increases the likelihood of catastrophic avian mortality events during extreme heat waves. - Biol. Lett. 6: 253-256.

McKechnie, A. E. et al. 2017. Avian thermoregulation in the heat: evaporative cooling in five Australian passerines reveals withinorder biogeographic variation in heat tolerance. - J. Exp. Biol. 220: 2436-2444.

Meehl, G. A. and Tebaldi, C. 2004. More intense, more frequent and longer lasting heat waves in the 21 st century. - Science 305 : 994-997.

Noakes, M. J. et al. 2016. Seasonal and geographical variation in heat tolerance and evaporative cooling capacity in a passerine bird. - J. Exp. Biol. 219: 859-869.

Puga-Gonzalez, I. et al. 2018. Mechanisms of reciprocity and diversity in social networks: a modeling and comparative approach. - Behav. Ecol. 29: 745-760.

Ramos, A. et al. 2019. The social network structure of a semi-free roaming European bison herd (Bison bonasus). - Behav. Processes 158: 97-105.
Rat, M. 2015. Dominance, social organisation and cooperation in the sociable weaver Philetairus socius. - $\mathrm{PhD}$ thesis, Univ. of Cape Town, Cape Town.

Rat, M. et al. 2020. Data from: Extreme and variable environmental temperatures are linked to reduction of social network cohesiveness in a highly social passerine. - Figshare Digital Repository, <https://figshare.com/s/6682542fdca315a109d1>.

Romano, V. et al. 2018. Social transmission in networks: global efficiency peaks with intermediate levels of modularity. - Behav. Ecol. Sociobiol. 72: 154.

Rubenstein, D. I. 1992. The greenhouse effect and changes in animal behavior: effects on social structure and life-history strategies. - In: Peters, R. L. (ed.), Global warming and biological diversity. Yale Univ. Press, pp. 180-192.

Rubenstein, D. R. and Lovette, I. J. 2007. Temporal environmental variability drives the evolution of cooperative breeding in birds. - Curr. Biol. 17: 1414-1419.

Ruel, J. J. and Ayres, M. P. 1999. Jensen's inequality predicts effects of environmental variation. - Trends Ecol. Evol. 14: 361-366.

Santee, W. R. and Bakken, G. S. 1987. Social displays in redwinged blackbirds (Agelaius phoeniceus): sensitivity to thermoregulatory costs. - Auk 104: 413-420.

Shen, S. F. et al. 2017. The ecology of cooperative breeding behaviour. - Ecol. Lett. 20: 708-720.

Silk, J. B. 2007a. The adaptive value of sociality in mammalian groups. - Phil. Trans. R. Soc. B 362: 539-559.

Silk, J. B. 2007b. Social components of fitness in primate groups. - Science 317: 1347-1351.

Silk, J. B. et al. 2003. Social bonds of female baboons enhance infant survival. - Science 302: 1231-1234.

Silk, M. J. 2018. The next steps in the study of missing individuals in networks: a comment on Smith et al. (2017). - Soc. Netw. 52: 37-41.

Smit, B. et al. 2013. Adaptive thermoregulation during summer in two populations of an arid-zone passerine. - Ecology 94: 1142-1154.

Smit, B. et al. 2018. Avian thermoregulation in the heat: phylogenetic variation among avian orders in evaporative cooling capacity and heat tolerance. - J. Exp. Biol. 221: jeb.174870.

Smith, J. A. et al. 2017. Network sampling coverage II: the effect of non-random missing data on network measurement. - Soc. Netw. 48: 78-99.

Spottiswoode, C. N. 2005. Sociable weaver. - In: Hockey, P. A. R. et al. (eds), Roberts birds of southern Africa. The Trustees of the John Voelcker, Cape Town.

Strobl, C. et al. 2008. Conditional variable importance for random forests. - BMC Bioinf. 9: 307.

Sueur, C. et al. 2017. Mechanisms of network evolution: a focus on socioecological factors, intermediary mechanisms and selection pressures. - Primates 60: 167-181.

Tanner, C. J. and Jackson, A. L. 2012. Social structure emerges via the interaction between local ecology and individual behaviour. - J. Anim. Ecol. 81: 260-267.

Thompson, M. et al. 2018. Interspecific variation in avian thermoregulatory patterns and heat dissipation behaviours in a subtropical desert. - Physiol. Behav. 188: 311-323.

Tyson, P. D. and Crimp, S. J. 1998. The climate of the Kalahari transect. - Trans. R. Soc. S. Afr. 53: 93-112.

van de Ven, T. et al. 2019. The cost of keeping cool: behavioural tradeoffs beween foraging and thermoregulation are associated with significant mass losses in an arid-zone bird. - Oecologia 191: 205-215. 
van Dijk, R. E. et al. 2013. The thermoregulatory benefits of the communal nest of sociable weavers (Philetairus socius) are spatially structured within nests. - J. Avian Biol. 44: $102-110$.

van Dijk, R. E. et al. 2015. Fine-scale genetic structure reflects sexspecific dispersal strategies in a population of sociable weavers (Philetairus socius). - Mol. Ecol. 24: 4296-4311.

van Wilgen, N. J. et al. 2015. Rising temperatures and changing rainfall patterns in South Africa's national parks. - Int. J. Climatol. 36: 706-721.

Vasse, M. et al. 2017. Antibiotic stress selects against cooperation in the pathogenic bacterium Pseudomonas aeruginosa. - Proc. Natl Acad. Sci. USA 114: 546-551.

Vasseur, D. A. et al. 2014. Increased temperature variation poses a greater risk to species than climate warming. - Proc. R. Soc. B 281: 20132612.
Viblanc, V. A. et al. 2016. Aggression in Columbian ground squirrels: relationships with age, kinship, energy allocation and fitness. - Behav. Ecol. 27: arw098.

Whitehead, H. and Dufault, S. 1999. Techniques for analyzing vertebrate social structure using identified individuals. - Adv. Study Behav. 28: 33-74.

Whitfield, M. C. et al. 2015. Avian thermoregulation in the heat: scaling of heat tolerance and evaporative cooling capacity in three southern African arid-zone passerines. - J. Exp. Biol. 218: 1705-1714.

Wiley, E. M. and Ridley, A. R. 2016. The effects of temperature on offspring provisioning in a cooperative breeder. - Anim. Behav. 117: $187-195$.

Wolf, B. 2000. Global warming and avian occupancy of hot deserts; a physiological and behavioral perspective. - Rev. Chil. Hist. Nat. 73: 395-400. 